\title{
COMPRESSIVE BEHAVIOUR OF BONDED BRICKWORK WALLETTES WITH VARIOUS THICKNESSES: EXPERIMENTAL AND NUMERICAL VERIFICATION
}

\author{
JULIAN THAMBOO*, MOHAMMAD ASAD ${ }^{\dagger}$, AND TATHEER ZAHRA ${ }^{\dagger}$ \\ *Department of Civil Engineering, South Eastern University of Sri Lanka, 32360 Oluvil, Sri Lanka, \\ e-mail: jathamboo@seu.ac.lk, (*corresponding author) \\ $\dagger$ School of Civil and Environmental Engineering, Queensland University of Technology, 4000, \\ Brisbane, Australia \\ e-mail:m.asad@qut.edu.au, t.zahra@qut.edu.au
}

Keywords: Brickwork, Compressive Strength; Stress-strain response, Micro Modelling, Slenderness.

\begin{abstract}
Bonded brickwork loadbearing walls are commonly seen in many colonial period structures around the world; however, most research studies in the past and the current design provisions are primarily based on single leaf brickwork. Due to the anisotropic nature of brickwork, the strength and deformation characteristics would be different for bonded brickwork walls and their design using the provisions of single leaf bonded brickworks may be un-conservative. Therefore, to understand the compressive behaviour of differently bonded brickworks, an experimental programme followed by a numerical investigation were carried out in this research. The experimental programme comprised of testing nine wallettes under uniaxial compression. Three different types of bonded thicknesses (single, double and triple) were used to construct the wallettes. The experimental results are presented and discussed in terms of failure modes, compressive strengths and stress-strain responses obtained. Further a numerical investigation based on the micro modelling approach was employed to verify the experimental findings. The experimental and numerical modelling results indicate that the change in brickwork thicknesses does not significantly increase the compressive strength of the masonry. The increased number of weak perpend joints in the bonded brickwork wallettes, could be a reason of lower strength and thus, a general notion of increment in compressive resistance due to the reduction in slenderness is not applicable for bonded brickwork. Parametric analyses were also carried out and reported for different slenderness ratios to extend the understanding on the behaviour of bonded brickworks under compression.
\end{abstract}

\section{INTRODUCTION}

Brickwork is widely used as loadbearing element in many historical and modern structures around the world. Consequently, the compressive resistance and deformation characteristics of brickwork were extensively researched in the past at material and structural scales. Primarily the strengths of the constitutive materials (unit and mortar) play a major role in determining the compressive strength of brickwork [1-5]. The current design standards 
provide either expression or tabulated values to verify the compressive strength and Young's modulus of brickwork using the designated unit and mortar strengths/classes.

Generally, loadbearing brickworks are designed and built with many architectural bonding patterns resulting in different thicknesses depending on the design requirements. Particularly walls consisting of two or more brick thicknesses are generally found in historical structures. Despite various types of brickworks being constructed with different thicknesses, the compressive strength assessment is generally derived by testing single leaf brickwork prisms/wallettes and subsequently the design expressions/tables were developed from these test data. However it can be hypothesised, that the compressive strength characteristics of brickworks with various bonded thicknesses could be different to the brickwork with single leaf thickness as more weak joints exists [6-8], thus it demands systematic investigation.

Most of the research works carried out in this regard was on stone masonry, which constitutes quite complex morphology, where inner and outer leaves are made of different masonry types [9-11]. However, the bonded brickworks are also very common elements in the many clay brick masonry structures around the world. These buildings are often of historic importance and require intervention, thus understanding of their fundamental loadbearing behaviour is highly necessary. Subsequently an attempt has been made to investigate the compressive strength characteristics of bonded brickworks through experimental and numerical studies. The experimental programme comprised of testing nine bonded brickwork wallettes under uniaxial compression with three different thicknesses. Further, a Finite element (FE) experimental findings and parametrically investigate the influence of bonded brickwork.
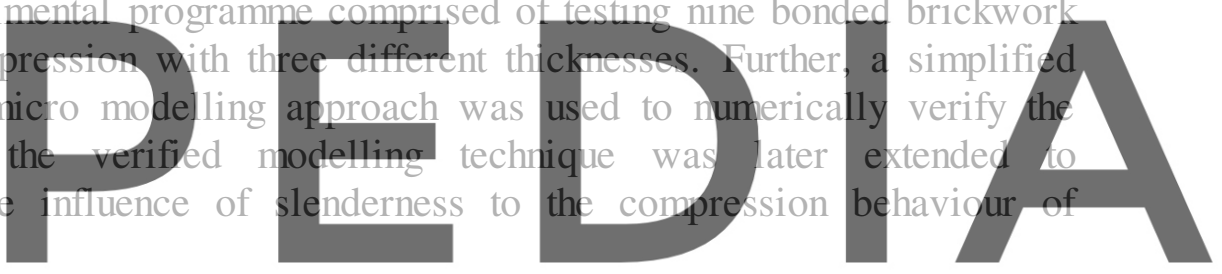

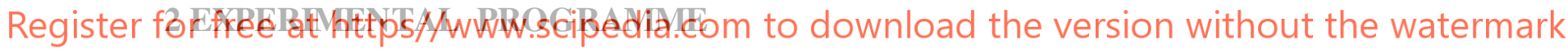

The wallettes in this experimental programme were constructed using a locally sourced low strength clay brick (CB), whose dimensional and mechanical properties resembles the brick types found in the colonial masonry structures in the Sri Lanka. A locally available Natural Hydraulic Lime (NHL) was used as the binder in this research similar to the NHL mortars found in the colonial masonry structures. The lime mortar mix was prepared using a binder to filler ratio of 1:3 by volume proportion. The measured compressive strengths and elastic moduli of the brick and mortar are given in Table 1 with the coefficient of variation in the parentheses. In total, nine masonry wallettes were constructed and tested as shown in Fig 1. For each unit-mortar-masonry thickness combination, three wallettes were built as per BS EN 1052-1 [12] provisions. The dimensions and notation of constructed wallette specimens are listed in Table 2. The dimensions of the triple thick brick wallettes slightly violated the outlined BS EN 1052-1 provisions, where the height of the wallettes was not more than three times the thickness. As the intention of the research was to compare the performance of masonry wallettes of different thickness and bonding pattern under compression, height of the wallettes were kept same for all cases and only the thickness was varied. The single brick thick wallettes were constructed with running bond and the double and triple thick wallettes 
were constructed with English bond which are the common bond patterns found in new and historical masonry structures.

Table 1: Mechanical properties of bricks and mortar.

\begin{tabular}{ccc}
\hline Specimen & Compressive Strength $(\mathrm{MPa})$ & Elastic modulus $(\mathrm{MPa})$ \\
\hline B1 & $5.1(9.5)$ & $4123(6.4)$ \\
\hline NHL & $2.4(5.6)$ & $1402(3.6)$ \\
\hline
\end{tabular}

Table 2: Test scheme and dimension of wallette specimens.

\begin{tabular}{|c|c|c|c|}
\hline Notation & Brick Type & Thickness & Dimensions $(\mathrm{mm})$ \\
\hline B1-S & \multirow{3}{*}{ B1 } & Single $(\mathrm{S})$ & $410(\mathrm{~L}) \times 740(\mathrm{H}) \times 95(\mathrm{~T})$ \\
\hline B1-D & & Double (D) & $410(\mathrm{~L}) \times 740(\mathrm{H}) \times 200(\mathrm{~T})$ \\
\hline B1-T & & Triple (T) & $410(\mathrm{~L}) \times 740(\mathrm{H}) \times 305(\mathrm{~T})$ \\
\hline
\end{tabular}

The compression testing was carried out using a $1000 \mathrm{kN}$ capacity servo-controlled universal testing machine. The wallettes were placed carefull the UTM to avoid any accidental eccentricity in loading. A 5 mim plywood ca

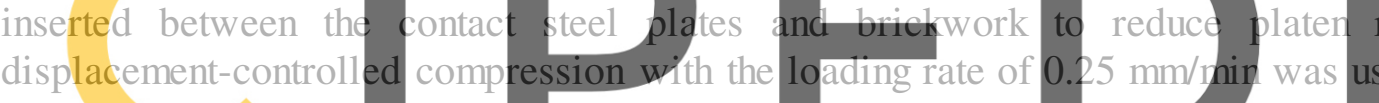
six displacement transducers were attached on the wallettes to capture the vertical a deformations of the wallettes under compression. Four displacement transducers (two per face) were attached to capture the axial deformation. Another two displacement transducers

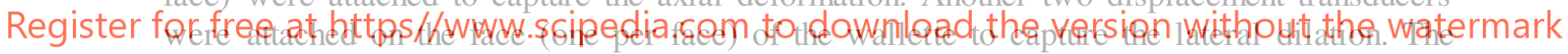
testing arrangements of single, double and triple brick thick wallettes are shown in Figure 1. More details of the experimental programme can be referred in Thamboo and Dhanasekar [13].

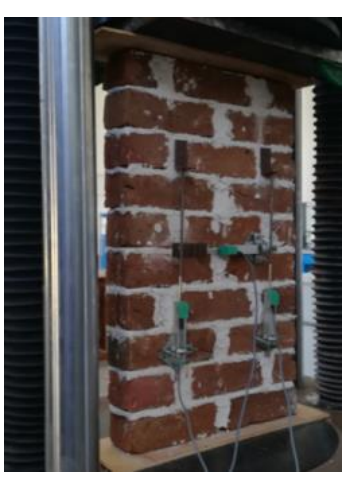

(a)

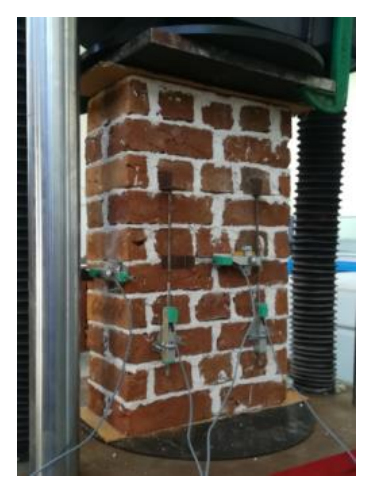

(b)

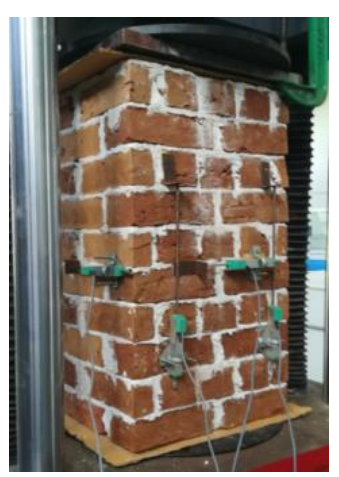

(c)

Figure 1: Compression testing of (a) single, (b) double and (c) triple brick thick wallettes. 


\section{EXPERIMENTAL RESULTS}

The failure modes were approximately similar across different thicknesses of wallettes tested under compression and shown in Figure 2. The failure of the wallettes were largely characterised by parallel vertical cracks originated at brick- mortar interface and propagated through the middle of the bricks. It must be highlighted that the double and triple thick brick wallettes showed predominantly single splitting cracks on the short sides along with the tensile parallel cracks on the long sides.

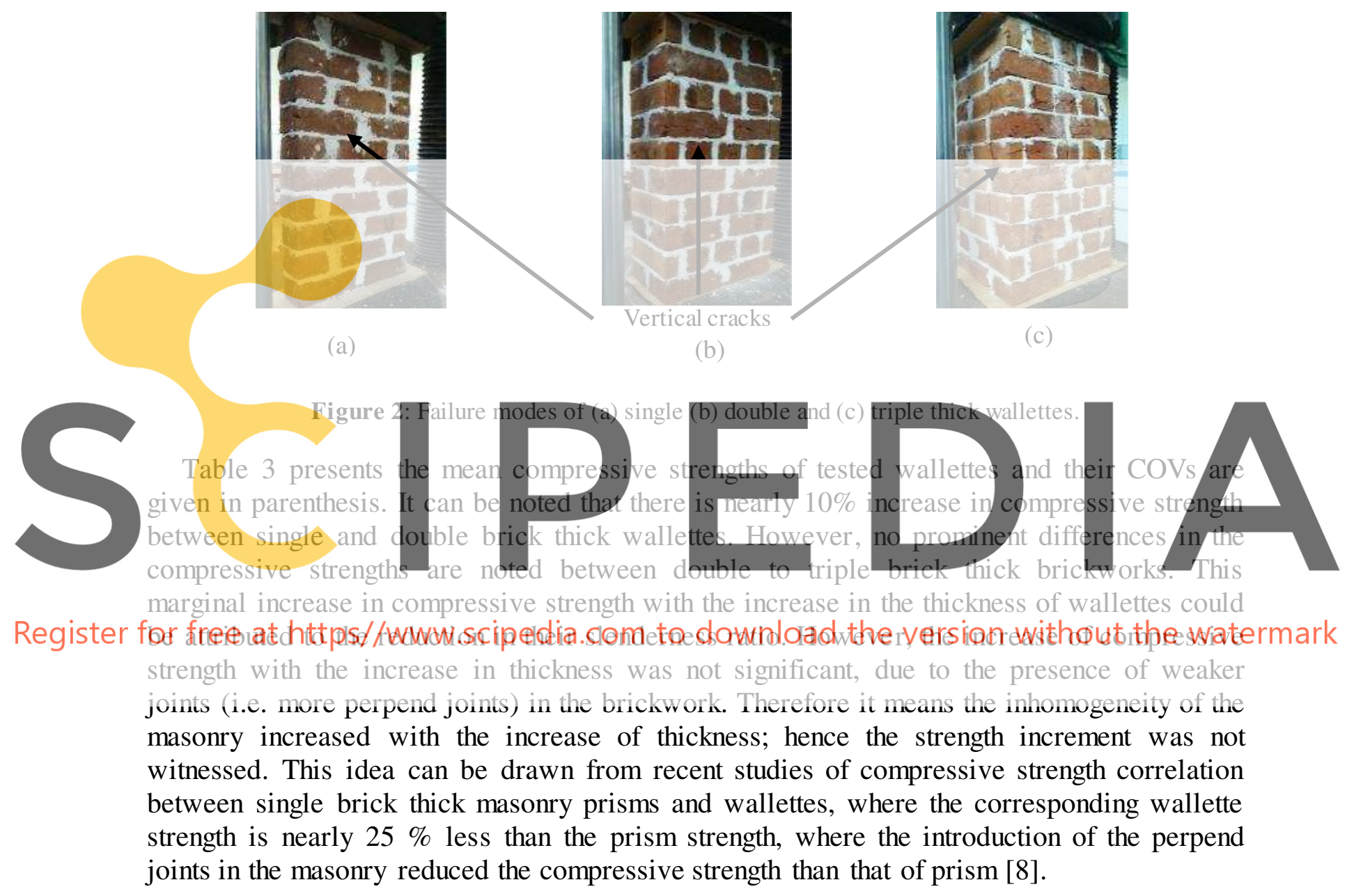

Table 3: Compressive strength and elastic properties of the tested wallettes.

\begin{tabular}{cccc}
\hline Notation & Compressive Strength (MPa) & Elastic modulus (MPa) & Poisson's ratio \\
\hline B1-S & $2.1(6.4)$ & $175(12.6)$ & $0.2(6.0)$ \\
\hline B1-D & $2.3(9.3)$ & $219(10.4)$ & $0.19(9.8)$ \\
\hline B1-T & $2.4(9.6)$ & $224(3.0)$ & $0.2(9.0)$ \\
\hline
\end{tabular}


The compressive stress-strain curves of the monotonically loaded wallettes have displayed approximately linear stress-strain behaviour up to 60 to $70 \%$ of the peak strength and afterward nonlinear behaviour was observed up to the failure. Moreover, the elastic, peak and ultimate strain measurements indicated a slight increase in the ultimate strain at failure in the triple brick thick wallettes than of single and double brick thick wallettes. The increase in inhomogeneity, thereby increase in weaker planes in the triple leaf masonry wallettes could have contributed to the increased deformation characteristics.

\section{NUMERICAL MODEL}

The experimental results of the wallettes were verified through a simplified FE based micro-modelling technique. This micro-model of bonded brickwork considers that the bricks are joined through equivalent contact interfaces to replicate the masonry behaviour without specifically modelling the mortar layers [14-15]. Therefore, the bricks are expanded to take the combined effect of brick and mortar and equivalent interfaces with zero thickness are modelled to simulate the combined mortar and mortar-brick contact behaviour as described in Figure 3. Subsequently, a three-dimensional (3D) FE model with plastically damaging nonlinear solid brick elements and zero thickness interface elements with cohesive and damaging properties was developed for each wallette. The ABAQUS finite element software [16] was used for the numerical simulations. The bricks were modelled using eight-nodded 3D elements (C3D8R). Top and bottom loading plates (similar to experiments) were also

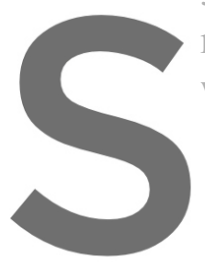
modelled as rigid body to
whilst the vertical transition $b$
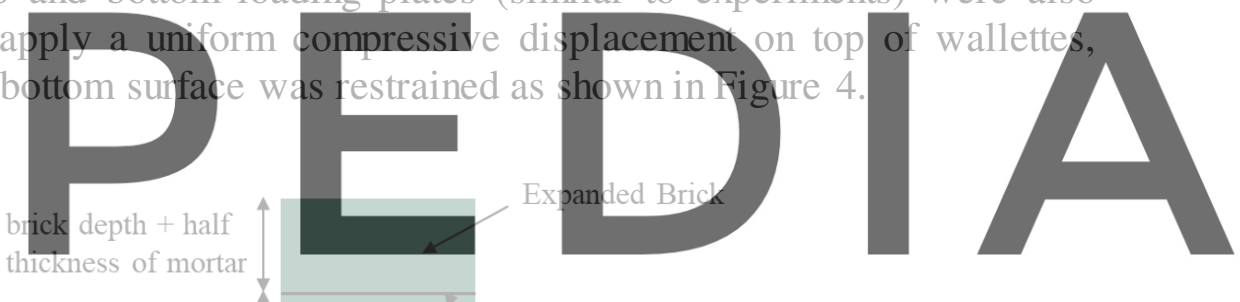

Register for free at https//www.sGilipededith. chalf

Figure 3: Meso-modelling concept of masonry.

A mesh size of $20 \mathrm{~mm} \times 20 \mathrm{~mm} \times 20 \mathrm{~mm}$ was employed for the brick elements after carrying out the mesh convergence studies. Material behaviour of the expanded clay bricks was simulated using 'Concrete Damage Plasticity Model' that includes the failure mechanism of tensile cracking and compressive crushing. The stress-strain properties taken for the bricks were calibrated based on the experimental test results of single brick wallettes as given in Thamboo and Dhanasekar [13]. Hence, the same material model was then employed to validate the results of double and triple wallette compression tests. The zero-thickness interaction was simulated using a constitutive law accounting for the traction-separation of the interface from the ABAQUS library. This model considers initially a linear elastic behaviour of the interface, which is followed by the initiation and evolution of interface damage. With the increase in compressive load, the stresses increase until the limiting stresses are assigned, after which friction model is activated which contributes to the shear stresses. Mohr-Coulomb failure criterion was used to model the friction behaviour. The interface parameters used for 
the contact modelling were taken from [17]. A uniform monotonic displacement of $10 \mathrm{~mm}$ was applied on the top of the loading plate with boundary constraints to simulate the compression tests as shown in Figure 4.
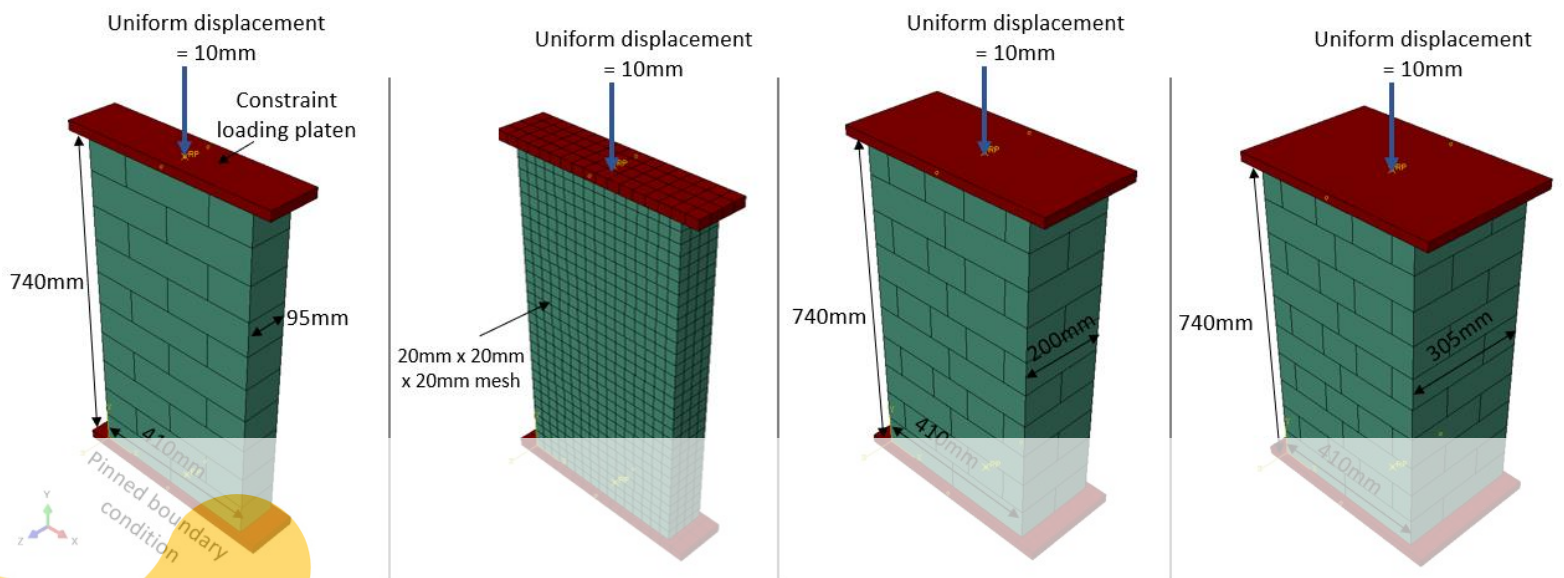

Figure 4: Wallettes model details (a) Single brick (b) Typical meshing (c) Double brick and (d) Triple brick wallette.

\subsection{Numerical Validation}

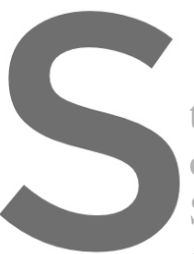

The outcome of the FE

tailure patterns observecand comp

of FE modelling of single, double and triple

Similar to experimental results, splitting cracks in

samples were observed. The failure strain levels are also same as that were observed in the

experimental results.

Register for free at https//www.scipedia.com to download the version without the watermark

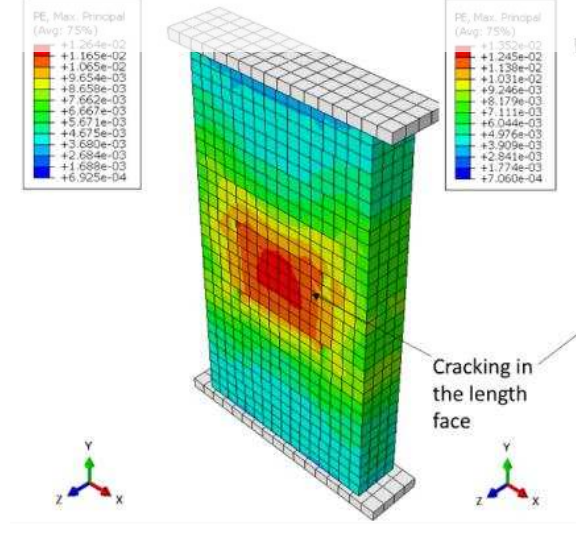

(a)

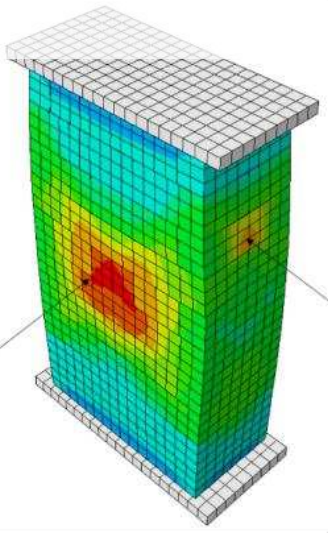

(b)

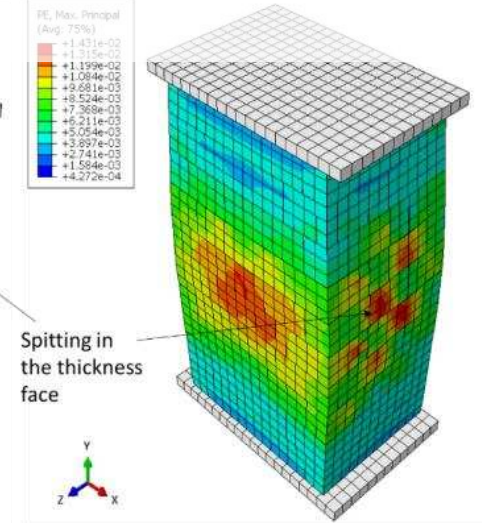

(c)

Figure 5: Failure modes of wallettes (a) Single brick (b) Double brick and (c) Triple brick. 
The stress-strain response validation for single, double and triple wallettes is presented in Figure 6. The overall stress-strain curves matched well with the experimental data. The prepeak and post peak behaviour of all wallettes was found similar to the experimental measurements. As discussed in the experimental results, not a significant difference in the strength due to change in bonded thicknesses was observed. This verifies that the increase in perpend joints in the thickness of double and triple walls affect the compressive behaviour of masonry.

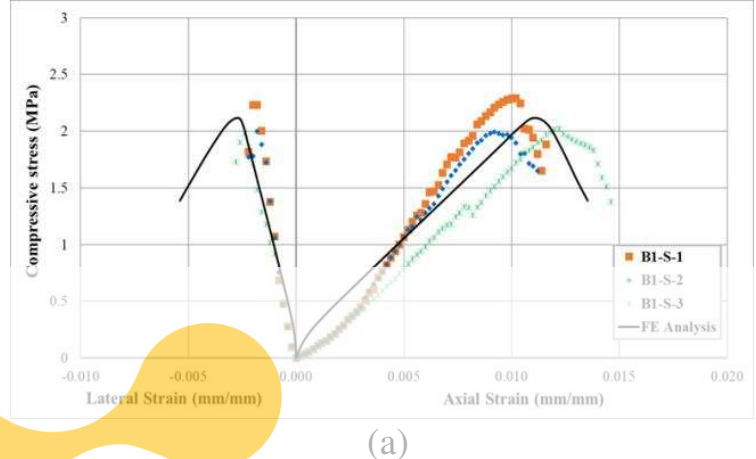

(a)
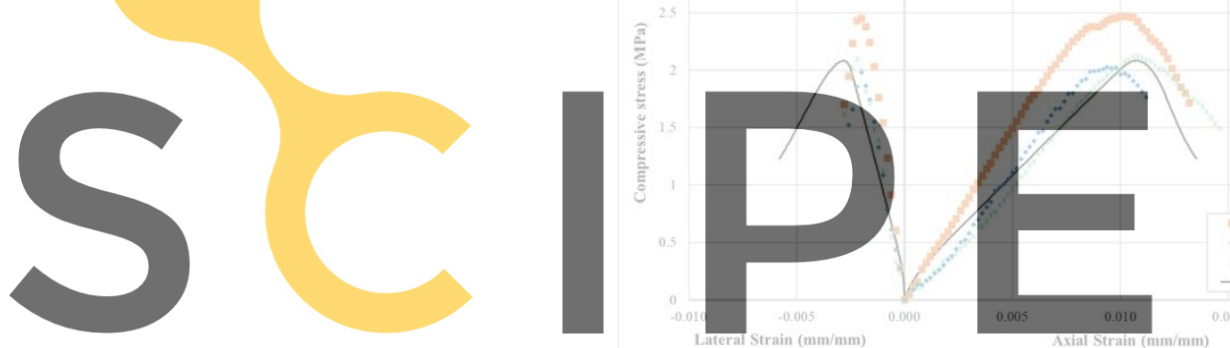

(c)

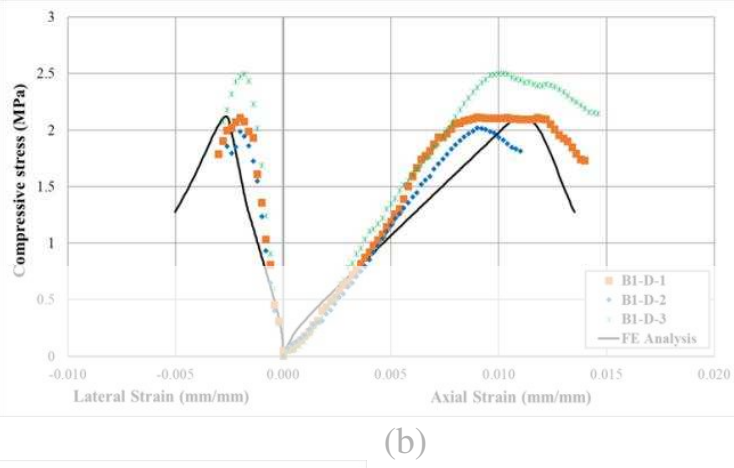

(b)
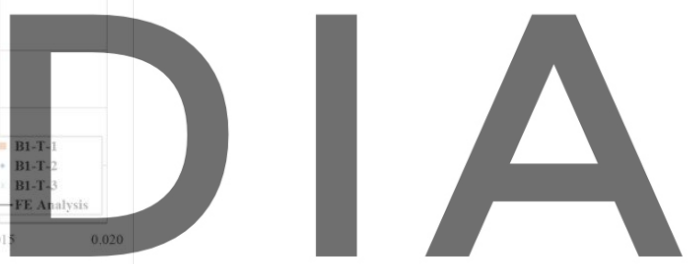

Register for free at https//www.scipedia.com to download the version without the watermark Figure 6: Stress-strain validation of wallettes (a) Single brick (b) Double brick (c) Triple brick

\section{PARAMETRIC STUDY}

The validated models of single, double and triple bonded brickwork wallettes were then employed to investigate the effect of the slenderness on the compressive behaviour of bonded brickworks. In the parametric study of bonded brickwork wallettes, the height of the wallettes was changed to $1040 \mathrm{~mm}$ to simulate different slenderness, in addition to the validated models. The $1040 \mathrm{~mm}$ height of the wallettes corresponds to the fifteen courses of brick layers. Subsequently, the corresponding slenderness ratio (height to thickness ratio, $h / t$ ) of the analysed single, double and triple bonded brickwork wallettes were 10.9, 5.2 and 3.4, respectively. The same constitutive material (i.e. brick and mortar) and interface properties that were considered for the model validation were used in the parametric study.

Figure 7 shows the failure pattern of the single, double and triple bonded brickwork wallettes with relatively higher slenderness than the previously analysed cases in section 4 . It could be said that the failure modes of the wallettes did not significantly change as the 
slendernesses, of the wallettes were increased by about 1.5 times from the previously analysed cases, where predominant tensile dilation of the masonry wallettes was noted regardless of the considered bonded thicknesses. However, the compressive strengths of the bonded brickworks have dropped about 5-10\%, when the slenderness was increased by 1.5 times. The compressive strengths obtained in the parametric study are given in Table 4 . In order to verify the strength variation in the bonded brickworks with different slenderness values, the compressive strength obtained were normalised with respect to the strength of single brick thickness wallette of $740 \mathrm{~mm}$ height. It can be seen that the change in bonded thickness (single, double and triple) in the 1040 high wallettes did not change the compressive strength of the masonry, thus it confirms that the general notion of increase in compressive strength with the reduction in slenderness of the masonry is not applicable for bonded brickworks.

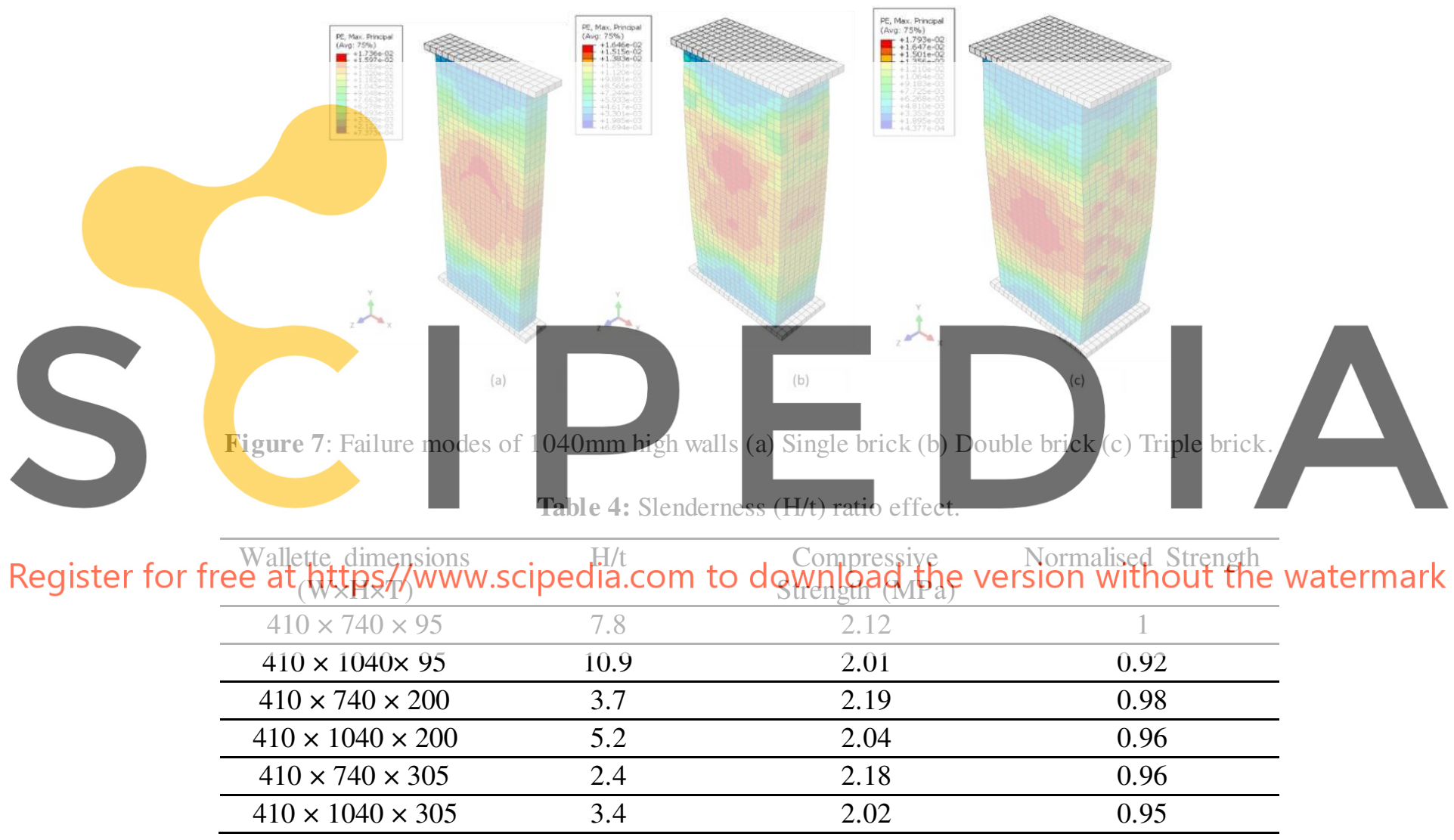

However, changing the slenderness by changing the height of the wallettes have reduce the compressive strength in all the thicknesses analysed, which is in agreement with the common understand of the behaviour of masonry under axial compression. Therefore, it could be stated, that for the bonded brickworks, the slenderness increment due to increase in thickness should be carefully assessed to verify the compressive resistance. Further experimental and numerical studies have to be carried out to develop correction factors to adjust the compressive strengths of the bonded brickworks with various masonry assemblies and slenderness ratios in the future, similar to the correction factors for masonry prism test [18]. 


\section{CONCLUSIONS}

The compressive strength characteristics of bonded brickworks were assessed through experimental and numerical studies. Subsequently, single, double and triple thickness bonded brickwork wallettes were assembled with lime mortar to replicate the historical masonry buildings, and tested to ascertain the strength, failure and complete stress-strain response. The limited experimental testing results have shown that the change in thickness of the brickwork did not significantly change the failure pattern and as well as the strength characteristics, which is against the common notion of that as the reduction in slenderness would increases the compressive strength of masonry, however this phenomenon in bonded brickwork is due to anisotropic nature of masonry, where with increase in thicknesses, increases the inhomogeneity with the presence of more joints in the masonry, subsequently no substantial strength increment could be achieved.

Subsequently in order to verify the experimental findings, a FE based micro-modelling technique was developed to model bonded brickwork tested in this research and the established modelling technique was validated with the experimental results in terms of failure patterns and compressive stress-strain curves. Later the validated FE modelling method was extended to parametrically analyse the effects of different heights of the bonded brickwork wallettes, and the results indicate that with the increase height (thereby slenderness) reduce the compressive resistance with in the same thickness of the wallettes. Therefore, the influence of bonded thickness of the brickwork should be cautiously verified to
determine the compressive resistance of bonded brickwork walls. Hence the experimental and
numerical studies have to be extended to develop correction factors to adjust the compressive
strength of bonded brickwork with various bri ckwork assembly properties and slendernesses,
similar to the correction factors for masonry prism test [18].

Acknowledgements. The technical assistance provided by Mr Mohamed Jiffry, Mr Mohamed

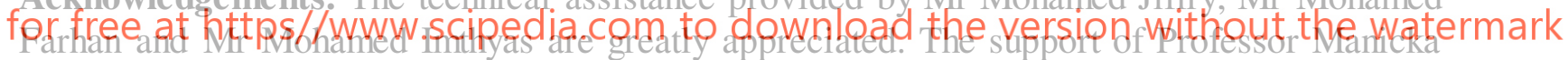
Dhanasekar is acknowledged. This research was funded by the South Eastern University of Sri Lanka under the grant number SEU/ASA/RG/2019/02.

\section{REFERENCES}

[1] Bennett, R.M., Boyd, K.A., and Flanagan, R.D. Compressive properties of structural clay tile prisms. J. Struct. Eng (1997) 123(7): 920-926.

[2] Thamboo, J.A. and Dhanasekar, M. Behaviour of thin layer mortared concrete masonry under combined shear and compression. Aust. J. Struct. Eng (2016) 17(1): 39-52.

[3] Zahra, T. and Dhanasekar, M. Prediction of masonry compressive behaviour using a damage mechanics inspired modelling method. Constr. Build. Mater (2016) 109: 128138.

[4] Pelà, L., Canella, E., Aprile, A., and Roca, P. Compression test of masonry core samples extracted from existing brickwork. Constr. Build. Mater (2016) 119: 230-240.

[5] Segura, J., Pela, L. and Roca, P. Monotonic and cyclic testing of clay brick and lime mortar masonry in compression. Constr. Build. Mater (2018) 193: 453-466. 
[6] Gumeste, K.S. and Venkatarama Reddy, B.V. Strength and elasticity of brick masonry prisms and wallettes under compression. Mater. Struct (2007) 29: 241-253

[7] Zahra, T. and Dhanasekar, M. A generalised damage model for masonry under compression. Int. J. Damage Mech. (2016) 25(5): 629-660.

[8] Thamboo, J.A. and Dhanasekar, M. Correlation between the performance of solid masonry prisms and wallettes under compression. J. Build. Eng (2019) 22: 429-438.

[9] Valluzzi, M.R., Da Porto, F. and Modena, C. Behavior and modeling of strengthened three-leaf stone masonry walls. Mater. Struct (2004) 37(3): 184-192.

[10] Binda, L., Pina-Henriques, J., Anzani, A., Fontana, A. and Lourenco, P.B. A contribution for the understanding of load-transfer mechanisms in multileaf masonry walls: Testing and modelling. Eng. Struct (2006) 28: 1132-1148.

[11] Oliveira, D.V. and Lourenço, P.B. Experimental behaviour of three-leaf stone masonry walls The construction aspects of built heritage protection, Dubrovnik, Croatia 2006 (2006) 356-362.

[12] BS EN 1052-1:1999 Methods of test for masonry. Determination of compressive strength, BSI.

[13] Thamboo, J.A. and Dhanasekar, M. Assessment of the characteristics of lime mortar bonded brickwork wallettes under monotonic and cyclic compression. Const. Build. Mater (2020) 261: 120003.

[14] Nazir, S. and Dhanasekar, M. Modelling the failure of thin layered mortar joints in masonry. Eng. Struct (2013) 49:615-627

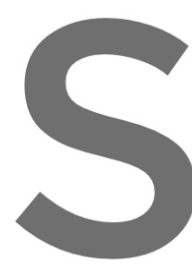

15] Bolhassani, M.,

16] ABAQUS, Finite 2018.

[17] Zahra, T. and
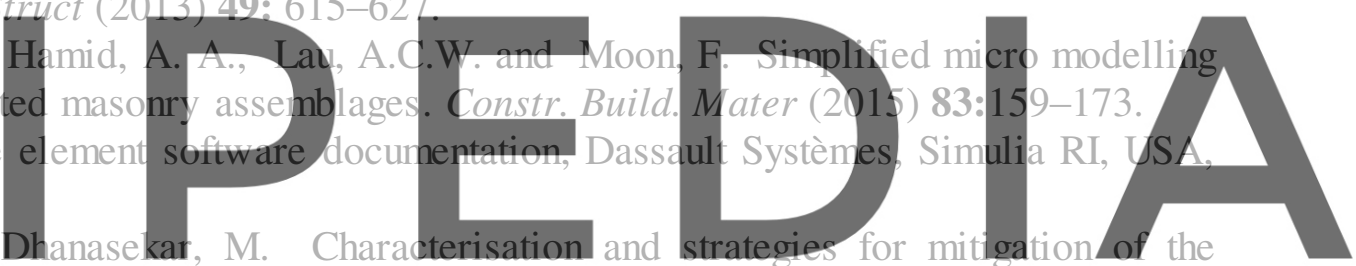

contact surface unevenness in dry-stack masonry. Constr. Build. Mater (2018) 169:612-

Register for frezeat https//www.scipedia.com to download the version without the watermark

[18] ASTM C1314 - 14 Standard Test Method for Compressive Strength of Masonry Prisms, ASTM International, USA. 